\title{
Levantamento das necessidades e elaboração de plano de treinamento e desenvolvimento para empresa de TI
}

\section{Resumo}

Este artigo tem como objetivo identificar e elaborar um plano de treinamento e desenvolvimento juntamente aos colaboradores de uma empresa de TI. Metodologicamente, trata-se de um estudo de caso através de pesquisa descritiva com abordagem qualitativa e quantitativa com aplicação de questionários a 65 colaboradores e gestores. Neste estudo foi elaborada uma matriz que permite a visualização de quais treinamentos disponibilizar para seus colaboradores. A utilização dessa matriz T\&D, trás oportunidades de crescimento pessoal e profissional, bem como aumenta o desempenho na realização das funções o que consequentemente aumenta a produtividade, refletindo sobremaneira na qualidade dos serviços prestados pela organização.

Palavras-chave: Treinamento e Desenvolvimento; Tecnologia da Informação; Colaboradores.

\section{Needs assessment and concoction of training and development plan for IT company}

\section{ABSTRACT}

This article aims to identify and develop a training and development plan along to the employees of an TI company. Methodologically, it is a case study through descriptive research with qualitative and quantitative approach with questionnaires to 65 employees and managers. In this study we created a matrix that allows the visualization of which provide training for its employees. The use of this $T \& D$ matrix, back opportunities for personal and professional growth as well as increases performance in carrying out the functions which in turn increases productivity, reflecting greatly on the quality of services provided by the organization.

Key-words: Training and Development; Information Technology; Employees.

(1) Sociedade Educacional Três de Maio, Rio Grande do Sul (brunaprumke@gmail.com)

(2) Sociedade Educacional Três de Maio, Rio Grande do Sul (dionir_tup@hotmail.com)

(3) Mestrado em Engenharia de Produção pela Universidade Federal de Santa Maria (2013) Professor efetivo assistente nível 1. Mestre da Universidade Regional do Noroeste do Estado do Rio Grande do Sul (adriane.fabricio@unijui.edu.br)

(4) Mestranda em Administração pelo Programa de Pós-Graduação em Administração da Universidade Federal de Santa Maria (sandraobregon12@gmail.com)

(5) Doutor em Engenharia de Produção pela Universidade Federal de Santa Catarina e professor Associado do Depto de Ciências Administrativas da Universidade Federal de Santa Maria (Iflopes67@yahoo.com.br) 


\section{INTRODUÇÃO}

No contexto organizacional, no qual o setor de serviços está tomando conta do mercado de trabalho e se tornando cada vez mais competitivo, é de suma importância que as empresas estejam atentas e ofereçam serviços de qualidade. Em razão disso, perceber se os colaboradores estão qualificados para realizar um atendimento de maneira eficaz, é essencial para o sucesso da empresa.

Nesse sentido, a definição das habilidades necessárias para cada cargo e as tarefas a serem executadas são muito importantes tanto para o colaborador quanto para a organização, pois é através delas que ocorre o melhor desempenho das atividades. Além disso, realizar avaliação de desempenho de cada colaborador proporciona retorno ao mesmo fazendo com ele perceba seu desempenho no trabalho e sinta-se valorizado e motivado.

No que tange a área de Tecnologia da Informação ( $\mathrm{TI})$, a atualização e treinamentos são fundamentais, pois as mudanças são constantes em vista que a legislação vigente muda constantemente fazendo com que os programas oferecidos pelas empresas necessitem de adaptação, bem como a empresa precisa antecipar-se às principais necessidades do cliente, para que o serviço esteja sempre de acordo com as suas expectativas. Desta forma, os profissionais desta área carecem de qualificação e treinamentos constantes para realizar o atendimento transmitindo segurança e confiabilidade.

Ressalta-se ainda que para haver fidelidade por parte do cliente à empresa é necessário que essa atualização envolva tanto os gestores quanto os colaboradores, para que haja harmonia no conhecimento e transições de informações. Nesse sentido, Boog (2001, p.29) corrobora com a seguinte explanação:

Se há uma unanimidade nas organizações, é a de que é preciso treinar as pessoas. Qualquer gerente, desde o encarregado de primeira linha até o presidente, não precisa de muito estímulo para desfiar uma série de problemas que não aconteceriam se as pessoas sob sua responsabilidade estivessem melhor preparadas.

Sendo assim, o treinamento e a qualificação do colaborador trarão muitos benefícios para a organização, dentre eles o aumento da satisfação e fidelização dos clientes em virtude de um atendimento qualificado. Deste modo, este estudo tem como objetivo realizar um levantamento das necessidades e elaboração de um plano de treinamento e desenvolvimento para uma empresa de Tecnologia da Informação ( $\mathrm{TI}$ ). Através da identificação, é possível sugerir quais treinamentos e desenvolvimentos necessários para que a organização consiga melhorar a qualidade do serviço prestado e auxiliar o colaborador a melhorar a sua produtividade.

\section{REFERENCIAL TEÓRICO}

\subsection{GESTÃO DE PESSOAS}

Há muitos anos as organizações vêm enfrentando desafios, tanto ambientais quanto organizacionais, muitos destes decorrentes da globalização econômica e do desenvolvimento tecnológico e competitivo. E para enfrentar essas mudanças as empresas precisam utilizar ao máximo do seu potencial humano, sendo esses tratados como parceiros da organização e reconhecidos como fornecedores de conhecimento e habilidades (GIL, 2001).

Para o autor, a gestão de pessoas tem como principal objetivo realizar a gestão de talentos, gestão de parceiros, gestão de capital humano, gestão de capital intelectual entre outros, trazendo à organização a maior participação do trabalhador nas decisões da organização.

Percebe-se que há uma necessidade muito grande de compreender as interações e relações dos sujeitos, a forma com que eles, em sua particularidade reagem às inúmeras 
transformações, pois afetam a maneira como a gestão de pessoas irá reagir e trabalhar no ambiente organizacional. Por isso, a gestão de pessoas necessita de uma constante reflexão sobre as tendências no modo como a sociedade se configura, sem perder a ligação com o individuo e seu comportamento no cotidiano (MARRAS, 2010).

Nesta perspectiva, um dos maiores desafios das organizações está em lidar com as pessoas, o gestor precisa estar apto à isto. Assim, as organizações eficientes possuem sólida estrutura de suporte ao gestor através do departamento de $\mathrm{RH}$, provendo mecanismos de avaliação de desempenho, programas de treinamento, entre outros. Todavia, tudo o que a empresa ofertar ao funcionário é em vão se o gestor não fizer seu papel de também compreender que está trabalhando com pessoas e, que o resultado e desempenho da organização dependem delas (XAVIER, 2006).

O acirramento da competitividade, a exigência dos clientes cada vez maior por bens e serviços de qualidade, bem como adequados as suas expectativas, exigem que as empresas invistam nos processos internos e, principalmente, que desenvolvam ações em busca de reter e qualificar os profissionais. Em razão disso, produtividade e qualidade dos produtos e serviços para a empresa estão ligados diretamente a qualificação dos colaboradores que os produzem. Portanto, a qualificação destes garantem a empresa maior competitividade no mercado, garantindo destaque na aceitação de seus produtos e serviços e, otimização na sua rentabilidade (MARRAS, 2010).

Além disso, Marras (2010, pg 135) destaca que "A possibilidade de ampliar seus conhecimentos leva os trabalhadores a permanecer na empresa, diminuindo a taxa de turnover e absenteísmo, o que representa uma enorme vantagem sobre a concorrência". Porém, para que este cenário mencionado torne-se realidade, se faz necessário que a "gestão estratégica de pessoas consiga elaborar uma política de desenvolvimento que permita perceber determinada igualdade de condições na trajetória de ascensão das partes (empresa-empregado)". Essa velocidade de ascensão do desenvolvimento dos colaboradores precisa ser percebido em proporções consideradas justas, sob pena do descrédito ou desmotivação dos funcionários em relação às reais intenções da empresa (MARRAS, 2010, pg 135).

O autor Xavier (2006) corrobora afirmando que o problema e a solução das empresas são as pessoas, sendo de grande responsabilidade do gestor e dos profissionais de RH. Assim, o papel do gestor é manter um bom relacionamento com a equipe, observar, conversar, negociar, pactuar e ouvir de modo que haja uma interação para que a empresa esteja em pleno funcionamento a partir das competências organizadas de seus funcionários. E cabe ao $\mathrm{RH}$ prestar auxilio ao gestor nas suas demandas promovendo treinamento, comunicação a nível institucional, programas e politicas que permitam sintonia com as demandas estratégicas da organização.

Nesse sentido, para auxiliar na gestão das pessoas, ao passar dos anos foram criados subsistemas de gestão de pessoas, que auxiliam as empresas no entendimento das práticas que apoiam a gestão e, na tomada de decisão de que práticas melhor se adaptam a sua realidade organizacional.

\subsubsection{Subsistemas de gestão de pessoas}

O surgimento da Administração de Recursos Humanos (ARH) se deu através do surgimento de conceitos trazidos pela teoria geral dos sistemas à gestão de pessoas, demonstrando que alguns princípios existentes em algumas ciências podiam ser aplicadas em outras áreas, fazendo com que práticas incompreendidas por uma área e muito utilizada por outra fossem vistas sob uma visão integradora. Por isso, a abordagem da administração de recursos humanos é considerada sistêmica, pois é vista como um conjunto de elementos unidos por 
alguma interdependência (GIL, 2001).

$\mathrm{Na}$ visão do mesmo autor, todas as empresas que mantém um setor de recursos humanos desenvolve uma gestão sistêmica de seu pessoal. A esses elementos se dá o nome de Subsistemas de Recursos Humanos, sendo estes responsáveis pelas políticas e práticas aplicadas na administração de pessoas dentro do ambiente de trabalho, mostrandoIhes os valores da empresa e contribuindo para o aumento da produtividade e resultados da organização como um todo.

Nesta perspectiva, Chiavenato (2009) ressalta a existência de cinco subsistemas de recursos humanos:

1) Processos de agregar pessoas: este processo engloba todas as atividades realizadas com o intuito de suprir a demanda de pessoas na empresa através da inclusão de novos funcionários. Envolve o planejamento incluindo pesquisa de mercado de recursos humanos, recrutamento e seleção de pessoas e a integração destas pessoas em seu novo ambiente de trabalho.

2) Processos de aplicar pessoas: inclui, dentre outras atividades, o desenho de cargos, que define o que os profissionais farão dentro da organização, orientação e acompanhamento do desempenho dos funcionários em suas atividades.

3) Processos de desenvolver pessoas: neste processo estão inseridas as atividades voltadas para a capacitação e desenvolvimento pessoal e profissional do funcionário, como treinamentos, programas de mudança e plano de carreira entre outros.

4) Processos de manter pessoas: está relacionado com a criação de um ambiente onde existam condições tanto ambientais como psicológicas satisfatórias para que o funcionário desenvolva suas tarefas e se sinta bem dentro da organização. Essas condições englobam a administração de salários, plano de benefícios e serviços sociais, segurança e medicina do trabalho, relações sindicais, qualidade de vida no trabalho, clima organizacional e todas as formas de recompensa que a empresa oferece.

5) Processos de monitorar pessoas: tem por objetivo acompanhar e controlar as atividades das pessoas e verificar os resultados. Incluem bancos de dados, sistemas de informações gerenciais e todo o tipo de controle, como frequência, produtividade, etc.

Ressalta-se que esses cinco subsistemas formam um processo global e dinâmico através do qual as pessoas são captadas e atraídas, aplicadas em suas tarefas, mantidas na organização, desenvolvidas e monitorizadas pela organização. Assim, esses subsistemas de recursos humanos não seguem uma sequência lógica, pois variam de acordo com a organização e dependem, além disso, de fatores ambientais, humanos, tecnológicos etc. Contudo, a ordem em que acontecem dentro das organizações não causa nenhuma influência na execução de cada (CHIAVENATO, 2009).

O autor Xavier (2006) define algumas etapas para o processo de gestão de pessoas e através delas busca respostas para saber como se chega a uma equipe de alto desempenho e as tarefas que têm de ser feitas pelo gestor para montar essa equipe, são elas:

1) Busca: para começar é imprescindível buscar as pessoas certas para integrar a equipe interna ou externamente. A partir de uma abordagem consolidada por Frederick W. Taylor em sua abordagem sobre a administração científica: "é preciso colocar o homem certo no lugar certo (the right man in the right place)". Tomando a partir desta citação nos dias atuais o sentido mais amplo de gênero humano.

2) Retenção: as pessoas precisam querer permanecer nas equipes, não basta 
buscar as pessoas certas. É imprescindível que elas desejem permanecer. Se faz necessário um "contrato psicológico" entre gestor, indivíduo e equipe.

3) Desempenho: cada indivíduo precisa fazer a sua parte e a pessoa responsável pela verificação é o gestor. Ele tem a responsabilidade de orientar para melhor e mais eficaz conduta dos seus subordinados. São diversos os ingredientes que têm de ser adicionados para que o bom desempenho se verifique: comunicações claras, motivação, treinamento, etc.

4) Desenvolvimento: finalmente, devido às exigências externas mudarem constantemente é necessário que cada indivíduo cresça e, é papel do gestor de criar condições para que isso aconteça, pois se seus subordinados se mantiverem sem crescimento no seu desempenho, logo em seguida se mostrarão insatisfeitos e, as consequências podem ser muito negativas.

O autor Dutra (2002), propõe um modelo para o desenvolvimento da gestão de pessoas que tem como premissas as concepções de autores da área das décadas de 80 e 90 e também as práticas de empresas que se revelaram exemplos de sucesso nesta. Tais ideias consistem no papel da gestão de pessoas:

- Desenvolvimento mútuo: tem papel de estimular e criar condições necessárias para que organização e indivíduos possam desenvolver-se mutuamente nas relações que estabelecem.

- Satisfação mútua: deve alinhar a um só tempo os objetivos estratégicos e negociais da organização e o projeto profissional e de vida dos indivíduos.

- Consistência no tempo: deve, também, oferecer parâmetros estáveis no tempo para que, dentro de uma realidade cada vez mais agitada, seja possível à organização e às pessoas obterem referenciais para se posicionar de forma relativa em diferentes contextos e momentos dessa realidade.

O autor Dutra (2002), elegeu uma balança para representar este modelo de gestão de pessoas proposto por ele, representando o contínuo equilíbrio que deve ser perseguido entre organizações e pessoas. Neste modelo criado tanto as pessoas quanto organizações possuem um importante papel. Cabe às pessoas a gestão de seu desenvolvimento, de sua competitividade profissional e de sua carreira. Como resultado, as pessoas estão bem mais conscientes de seu papel e passam a cobrar de si mesmas a gestão de suas carreiras, e das organizações as condições para o desenvolvimento profissional.

O autor defende que, desde o final dos anos 90 as pessoas passaram a dar maior importância a valorizar as oportunidades de desenvolvimento dentro das organizações e no mercado de trabalho. Assim sendo, os subsistemas de gestão de pessoas aqui abordados dão suporte a importância de se manter uma gestão organizacional pautada em técnicas e práticas que deem suporte ao gestor.

\subsection{Avaliação de desempenho}

A avaliação de desempenho é uma ferramenta que permite ao gestor estimar os resultados que um colaborador ou um grupo de colaboradores obtiveram em um período e área específicos, como por exemplo, os conhecimentos, metas, habilidades, entre outros adquiridos. Sendo que os objetivos desta avaliação é atingido no momento do retorno recebido, pois assim é possível visualizar os resultados trazidos pelo investimento realizados na carreira profissional do indivíduo (MARRAS, 2000).

A avaliação, na visão de Marras (2000), possui diversas utilidades, dentre elas, identificar os colaboradores que necessitam de aperfeiçoamento em determinado ponto, definir o grau de 
contribuição, tanto individual como grupal para com a organização, descobrir talentos, facilitar o autodesenvolvimento dos colaboradores, dar feedback aos colaboradores e contribuir com programas de mérito, promoções e transferências.

Como métodos de avaliação existentes, Marras (2000) cita as escalas gráficas, que são baseadas em fatores determinantes daquilo que a organização define como desempenho, são elas: Incidentes críticos, que analisa pontos positivos e negativos; Comparativo, que se utiliza de análises comparativas entre um e outro colaborador em relação ao grupo no qual ele atua; Escolha forçada, que são frases descritivas em relação a determinado desempenho, em relação às tarefas atribuídas ao colaborador e; 360 graus, em que o avaliado é o foco de todos os elementos que tenham relação com o mesmo: subordinados, superiores, pares, clientes internos e externos, fornecedores, etc.

Tachizawa, Ferreira e Fortuna (2001, p. 219) defende que "nenhuma organização consegue manter um bom nível de produtividade sem uma equipe de profissionais bem preparados", ou seja, o colaborador é a mente da empresa, que por sua vez é apenas um corpo que reflete o comportamento apresentado pelas pessoas que nela atuam. Quanto melhor uma pessoa, organização, indústria ou nação adquirir e aplicar conhecimentos, melhor será sua posição competitiva. A avaliação de desempenho deve ser utilizada para melhorar a produtividade do indivíduo dentro da organização, tornando-o mais bem equipado para produzir com eficácia e eficiência.

Marras (2000) define a avaliação de desempenho como métodos que medem o desempenho através de resultados mais para a visão quantitativa, isto é, resultados que são medidos através de metas atingidas e retorno recebido pela empresa. Os colaboradores que não atingem os resultados desejados devem ser treinados para que melhorem o seu desempenho e não prejudiquem a organização de nenhuma forma.

As empresas sobrevivem a partir de resultados e, estes são atingidos através de seus colaboradores. "Daí a afirmação de que o maior capital das empresas é o capital humano". Porém, este capital humano deve trazer resultados, pois acaso isso não ocorrer, a organização não conseguirá sobreviver para ela mesma, muito menos para seu capital humano (LEME, 2006, pg 7). Já a autora Bergamini (1987, p. 13) defende que "avaliar é de fato uma tendência humana natural. Todos nós, de forma empírica ou sistemática, estamos sempre analisando a nós mesmos e aos outros".

Ressalta-se ainda que no Brasil, a avaliação de desempenho tomou forma há mais de 50 anos e atualmente pode ser considerada como um dos mais importantes instrumentos que as empresas adotam para acompanhar a evolução dos seus colaboradores na organização. Os gestores, por sua vez, estão procurando cada vez mais desenvolver e adotar ações que elevem o comprometimento e os bons resultados dos seus empregados criando assim uma sinergia favorável ao desempenho produtivo da empresa, visto que as pessoas quando se sentem mais confiantes e motivadas realizam melhor suas funções, portanto, avaliar o desempenho permite avaliar através de indicadores a contribuição que o funcionário está oferecendo a organização.

\section{3 carreira}

A carreira é considerada uma sequência de cargos que o profissional irá ocupar dentro de uma organização, promovendo desta forma o desenvolvimento gradativo, em vista que ocupará ao decorrer do tempo, cada vez mais cargos elevados e consequentemente mais complexos. "Envolve uma série de estágios e a ocorrência de transições que refletem necessidades, motivos e aspirações individuais e expectativas e imposições da organização e da sociedade" (DUTRA, 1996, p. 17). 
Neste contexto, as perspectivas do funcionário e da organização em relação ao termo carreira possuem algumas diferenças. O funcionário tem a perspectiva de que carreira envolve o entendimento e avaliação da sua experiência profissional, quando a perspectiva da empresa envolve todas as políticas, procedimentos e decisões ligadas à organização, os níveis organizacionais e o movimento das pessoas dentro dela (DUTRA, 1996).

Para o mesmo autor, a empresa que almeja o desenvolvimento de carreira deve planejar o futuro de seus funcionários, focalizando naqueles que tem maior potencial para ocupar cargos superiores aos que ocupam no momento, não deixando de levar em consideração que os planos de carreira devem ser unilaterais, devem conter não apenas as necessidades da organização, mas também as necessidades das pessoas envolvidas.

Além disso, Araújo (2006) destaca que para uma pessoa planejar a sua carreira dentro da organização ela precisa ter claro alguns pontos, dentre eles:

- Conhecer suas as limitações, saber que existem limitações externas, trazidas pelo mundo e internas, causadas pelas próprias limitações de cada um;

- Definir uma meta, que vem a ser traçar um objetivo a ser alcançado, condizente com a realidade e observando as limitações.

- Não desviar o foco, tendo clareza sobre onde se quer chegar, determinando o caminho a ser percorrido.

- Planejar as ações, que conforme Araujo (2006, p. 127), "consiste, de forma bastante simples, em organizar, coordenar e controlar as ações que devem ser executadas com o intuito de se alcançar a meta pretendida".

Por fim destaca-se que todas as pessoas possuem uma carreira, pois ela é definida como um padrão de experiência profissional que se estenda por toda a vida do indivíduo. "Qualquer trabalho, remunerado ou não, realizado durante um período de tempo pode construir uma carreira". Além do emprego formal, pode também referir-se aos estudos, atividades autônomas e trabalho voluntário realizado (ROBBINS, JUDGE e SOBRAL, 2011, p. 459).

\subsection{Treinamento e desenvolvimento}

Quando trata-se de aprimorar e desenvolver pessoas e suas habilidades, o treinamento é a melhor alternativa a ser empregada, mas para que haja bons resultados é importante que os treinamentos sejam realizados com critérios bem definidos e de acordo com os objetivos que se quer alcançar. Conceituando, Marras (2009) ressalta que "treinamento é um processo de assimilação cultural a curto prazo, que objetiva repassar ou reciclar conhecimentos, habilidades ou atitudes relacionados diretamente a execução de tarefas ou à sua otimização no trabalho", ou seja, é uma ferramenta utilizada para transmitir conhecimento técnico a respeito de um produto ou serviço desenvolvido pela empresa.

O mesmo autor argumenta que uma empresa que investe em treinamento do seu pessoal garante que se tenha maior produtividade, melhor eficiência, economia de tempo e dinheiro, otimização dos resultados, melhor qualidade nos produtos ou serviços prestados e satisfação do colaborador.

Além disso, o desenvolvimento do colaborador é de extrema importância para o alcance dos objetivos da organização como um todo. E a obtenção de conhecimento, habilidades e atitudes, conhecidos como CHA, são um conjunto de qualidades oferecidas pelo homem, que podem ser aprimoradas com treinamentos e práticas, cada uma baseada em suas experiências (MARRAS, 2009). 
Portanto, empresas que almejam se tornar cada vez mais competitivas investem no treinamento de seus colaboradores, considerando que este é uma forma de desenvolver competências e torná-las mais criativas e inovadoras, que consequentemente contribuí efetivamente para a lucratividade da empresa. Assim, o treinamento é uma maneira de agregar valor às pessoas, à organização e aos clientes. Já o desenvolvimento possui um conceito mais abrangente, sendo voltado ao estímulo do crescimento pessoal dos colaboradores e ambos, são conceitos que atualmente vem ganhando uma atenção maior por parte das empresas pela sua importância e influencia no crescimento organizacional (MARRAS, 2009).

Quanto ao processo de treinamento e desenvolvimento, é uma forma de ação intencional com foco em fornecer meios para possibilitar a aprendizagem, em que esta pode ser definida como o processo de aquisição de experiência que leva a aumentar a capacidade e a alterar disposições de ações em relação ao ambiente que geram mudanças comportamentais (BOOG, 1994).

Treinamento é um processo metódico para promover o desenvolvimento de habilidades, regras, conhecimentos ou atitudes que tenham como resultado uma melhoria da adequação entre as características individuais dos funcionários e as exigências das tarefas funcionais (MILKOVICH E BOUDREAU, 2000).

Já o desenvolvimento tem maior relação com educação e foco no futuro, em que os processos de formação são mais aprofundados para que os indivíduos melhorem suas capacidades de compreensão e interpretação do conhecimento ao longo de suas vidas. $O$ desenvolvimento foca no desempenho futuro das pessoas e segundo Milkovich e Boudreau (2000, p. 121), "as empresas fazem uso de alguns métodos que auxiliam nesse processo como a participação em cursos e seminários, tutoria, coaching, rotação de cargos, posições de assessoria, atribuição de comissões, entre outros". Pode ser considerado como um processo mais longo de aperfeiçoamento das capacidades e motivação dos indivíduos com objetivo de torná-los futuros membros valiosos da organização. Ele inclui não apenas treinamento, mas também a carreira e, diversas outras experiências.

Nesse sentido, Araújo (2006) ressalta que é preciso que haja certa interação entre todos os membros envolvidos no processo de treinar e desenvolver pessoas, pois quem recebe o treinamento está se aperfeiçoando e desenvolvendo competências. Contudo, não havendo essa interação ou sendo ela muito fraca, prejudica os resultados e reduz as chances de sucesso nos programas de treinamento.

Dentre as vantagens que um programa de treinamento e desenvolvimento pode proporcionar, podem ser citados o ganho em competitividade e a melhoria contínua na qualidade. Além disso, existem várias outras vantagens como: ganho em competitividade e em qualidade; identifica os pontos fortes e fracos das pessoas e da organização como um todo; capacita as pessoas da organização; aumenta a lucratividade da empresa; racionaliza procedimentos e desenvolve pessoas; aumenta a produtividade; propicia um clima organizacional saudável; reduz desperdícios e retrabalho. Porém, para serem eficazes, os programas de treinamento e desenvolvimento devem ser planejados sempre considerando os prós e os contras e não somente pensando no lado positivo, isso porque cada empresa tem suas próprias características e particularidades (ARAÚJO, 2006).

As empresas não podem enxergar o treinamento e desenvolvimento apenas como um custo, mas sim como uma forma de manter sua competitividade, pois somente assim conseguirá garantir seu espaço no mercado, contando com a produtividade de profissionais capacitados que desempenham suas funções com excelência. 


\section{MÉTODO}

Tendo em vista que o estudo tem como objetivo identificar e realizar o levantamento das necessidades e elaboração de um plano de treinamento e desenvolvimento para uma empresa de Tecnologia da Informação (TI), utilizou-se de uma abordagem qualitativa, quantitativa e dedutiva.

A abordagem qualitativa foi utilizada para a interpretação das respostas subjetivas do questionário elaborado pelos próprios autores da pesquisa, a fim de explorar todas as informações coletadas. Além disso, as respostas dos colaboradores e dos gestores foram confrontadas para se chegar a um denominador comum e montar a matriz de T\&D. No que se refere abordagem quantitativa, através desta, os dados coletados foram analisados de forma numérica e estatística, observando a correlação das variáveis.

A empresa estudada conta atualmente com 65 colaboradores, incluindo os sócios proprietários. O questionário direcionado aos colaboradores foi enviado a todos os 65 , sendo que destes, 54 responderam a pesquisa, representando $83,08 \%$ da população. Já o questionário direcionado aos gestores, foi enviado a todos os 15 gestores, em que $100 \%$ deles responderam a pesquisa, correspondendo ao total da população. Para a coleta de informações sobre o levantamento das necessidades de treinamento e desenvolvimento junto aos colaboradores da empresa estudada, foi utilizado um questionário composto por 21 questões. Já para a coleta de informações junto aos gestores, foi aplicado um questionário composto por 15 questões. Para a aplicação da pesquisa, o grupo se utilizou da ferramenta Google Drive, que é um serviço de armazenamento e sincronização de arquivos, disponibilizado pelo Google. Através do Google Drive, os questionários foram enviados por e-mail aos colaboradores e gestores, em que estes acessaram as questões através de um link, e as respostas de cada um eram recebidas e armazenadas.

Já a respeito da abordagem dedutiva, partiu-se do pressuposto da existência de planos maiores de teorias e leis já existentes, chegando-se a premissas menores com resultados particulares, objetivando uma conclusão fundamentada no raciocínio da dedução sobre o levantamento das necessidades e elaboração de um plano de treinamento e desenvolvimento para uma empresa de TI (LOVATO, 2013).

Além disso, utilizou-se da pesquisa descritiva, que para Güllich, Lovato e Evangelista $(2007)$ têm como objetivo observar os fatos que acontecem na empresa estudada, registrálos, analisá-los, classificá-los e interpretá-los sem interferir. Ademais, a pesquisa classifica-se como um estudo de caso, que para Lovato (2013, p. 50), "neste delineamento o pesquisador foca num programa, evento ou atividade, envolvendo indivíduos. Há mais interesse nas atividades do grupo do que nas relações entre eles ou nos seus sentimentos", para que se conhecesse cotidiano da empresa estudada.

Após a coleta dos dados, elaborou-se uma matriz para que as necessidades de treinamento fossem visualizadas. Feito este mapeamento, foi elaborada uma ferramenta para que a empresa a utilize toda vez que um funcionário fizer algum tipo de treinamento, servindo como base para que se possa acompanhar a satisfação e desempenho dos colaboradores .

\section{4. análise dos resuLTADOS}

\subsection{A EMPRESA}

Atuando no mercado de TI desde 1989, no município de Três de Maio, noroeste do RS, a empresa vem tendo participação fundamental na informatização de estabelecimentos do setor público e privado, fornecendo as melhores inovações tecnológicas através de seus softwares aplicativos integrados. 
Inicialmente prestava serviços de birô para absorver as necessidades das empresas e prefeituras que ainda não estavam informatizadas. Estes serviços consistiam em digitação, processamento e emissão de relatórios para as áreas de gestão de pessoal, tributos, controles internos de cooperativas, entre outros.

Já no ano de 1992, a empresa começou a comercializar suprimentos de informática e passou a atuar no mercado de prestação de serviços técnicos com a instalação de equipamentos em rede para as prefeituras e cooperativas da região. Desde então, a empresa também é voltada ao desenvolvimento de softwares de alta qualidade e produtividade para o ramo de empresas privadas, características que estão alinhadas ao empenho de profissionais bem motivados que atuam em benefício dos clientes.

Atualmente a empresa conta com 65 colaboradores, sendo estes distribuídos em 15 setores, sendo eles: Desenvolvimento Educar Web, Desenvolvimento Gestor, Desenvolvimento Web, Financeiro, Gespam Contabilidade, Gespam Salutar, Gespam Tributos, Infraestrutura, Suporte Educar Web, Suporte Gestor, Administrativo, Comercial, Contabilidade, Departamento Pessoal e Implantação Educar Web.

Ressalta-se que até o momento a empresa não possui um setor de recursos humanos totalmente estruturado. Portanto, esta objetiva estruturar logo este setor para que esteja organizado a fim de atender aos assuntos pertinentes ao recrutamento e seleção, avaliação de desempenho, folha de pagamento, atração, retenção e desenvolvimento de recursos.

No entanto, apesar de não dispor de um setor de recursos humanos propriamente dito, a empresa possui colaboradores capacitados para fazer a folha de pagamento, recrutamento e seleção de candidatos para as vagas de trabalho que venham a surgir.

\subsection{Levantamento das necessidades de T\&d}

Devido às rápidas mudanças existentes no setor de TI é muito importante para os colaboradores a busca por conhecimento constante. O auxílio da empresa no aperfeiçoamento do conhecimento faz com que o colaborador sinta-se satisfeito ao saber que seu trabalho está sendo valorizado, em vista que o conhecimento adquirido pelos mesmos irá refletir em seu desempenho, trazendo à empresa as novidades do setor em que está inserido.

Dentre as vantagens que um programa de desenvolvimento pode proporcionar, citamse o ganho em competitividade e melhoria contínua na qualidade (ARAÚJO, 2006). Sendo assim, os funcionários foram questionados sobre o recebimento de treinamentos ao iniciar suas atividades na empresa em estudo, podendo ser visualizada as respostas na Figura 1.

Figura 1: Índice de colaboradores que receberam treinamentos ao ingressar na empresa

o colaborador recebeu treinamento ao iniciar suas atividades na empresa?

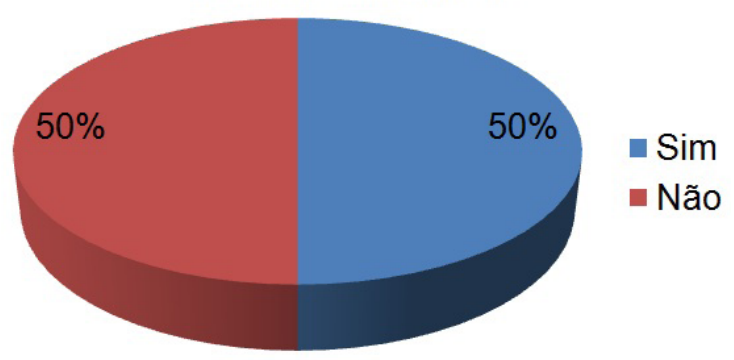


Percebe-se conforme a Figura 1, que $50 \%$ da amostra respondeu que sim, receberam treinamentos ao ingressar na empresa e $50 \%$ afirmou que não, o que demonstra a existência de algum tipo de treinamento, mas que provavelmente não seja aplicado em todos os setores da empresa ou nem todos são considerados treinamentos.

Do mesmo modo, os gestores foram questionados se os colaboradores receberam algum tipo de treinamento ao ingressar na empresa, conforme pode ser visto na Figura 2.

Figura 1: Visão gestor sobre o índice de colaboradores que receberam treinamentos ao ingressar na empresa

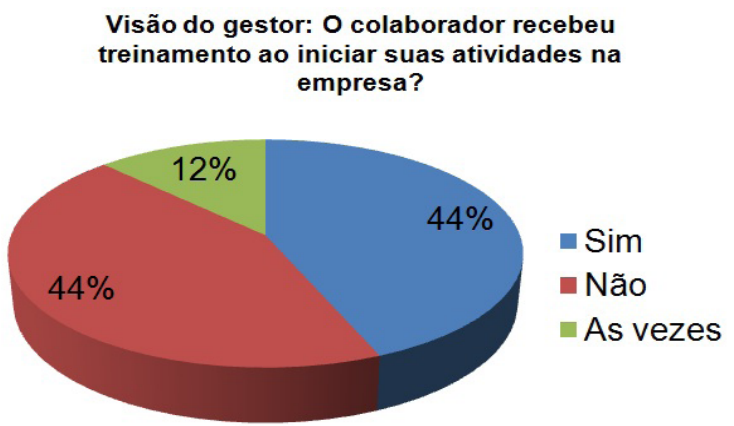

Contata-se na Figura 2, que 44\% dos gestores afirmam que o colaborador não recebe nenhum tipo de treinamento quando inicia suas atividades na empresa, outros $44 \%$ disseram que os colaboradores recebem sim algum tipo de treinamento e $12 \%$ afirmam que somente em algumas situações são aplicados treinamentos. Este resultado demonstra que em algumas ocasiões o colaborador está recebendo treinamento sem que o gestor de seu setor tenha conhecimento à respeito, sendo que este pode ser oferecido por um colega de trabalho ou pode estar sendo realizado durante o atendimento ao cliente através do esclarecimento de dúvidas e de acompanhamento da rotina do setor. Isso reforça a opinião dos colaboradores de que treinamento ao iniciar as atividades na empresa é muito importante para esclarecer pequenas dúvidas sobre o dia a dia do setor.

Percebe-se ainda que os colaboradores possuem uma visão diferente dos seus gestores em relação aos treinamentos realizados, porém as diferenças não podem ser consideradas grandes. Em algum momento os colaboradores podem se ajudar dentro de seu próprio setor, o que para eles pode ser considerado um tipo de treinamento, sem que o gestor esteja a par deste procedimento adotado pelos seus liderados.

Os T\&D são realizados a fim de realizar melhorias e pela busca por inovações nas organizações, mas isso é algo que não pode ser medido de forma imediata e sim haver uma melhora nos resultados em longo prazo, pois o principal objetivo é incentivar o colaborador através dos conhecimentos adquiridos, realizar o seu trabalho com maior dinamismo e desta maneira alcançar melhores resultados.

Deste modo, os colaboradores foram questionados se o treinamento e desenvolvimento melhora o desempenho na sua função, conforme pode ser conferido na Figura 3. 
Figura 2: Treinamento e desenvolvimento $\mathrm{x}$ desempenho do colaborador.

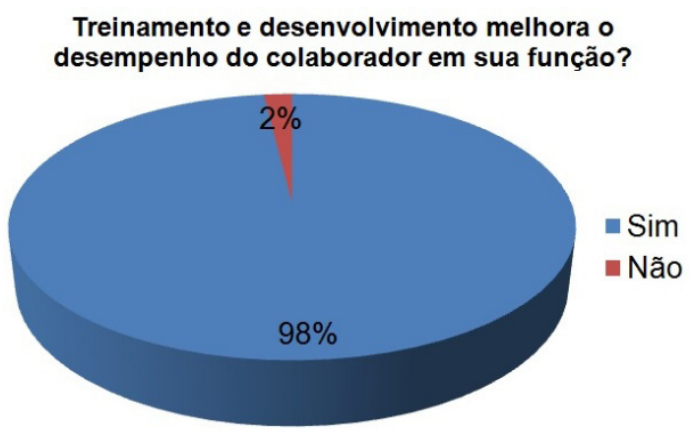

De acordo com a Figura 3, percebe-se que $98 \%$ dos colaboradores afirmaram que há uma melhora após a realização de treinamentos e somente $2 \%$ afirmam que não percebem melhora no seu desempenho após a sua participação em treinamentos.

Quanto à visão dos gestores sobre se os treinamentos e desenvolvimentos melhoram o desempenho dos colaboradores, pode ser visto na Figura 4.

Figura 3: Visão dos gestores sobre treinamento e desenvolvimento $\mathrm{x}$ desempenho do colaborador.

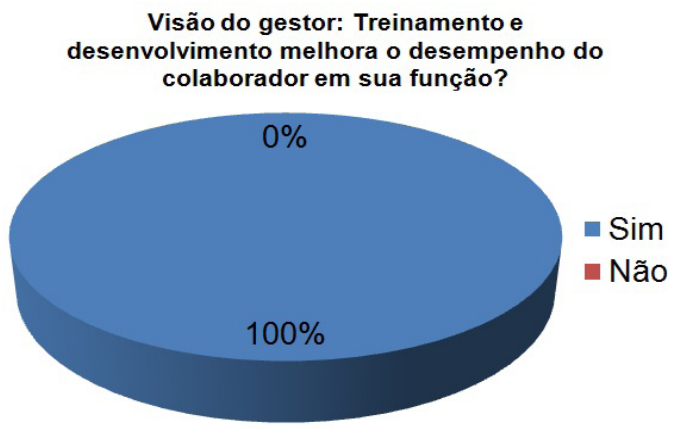

Constata-se que na opinião de $100 \%$ dos gestores (Figura 4), o treinamento e desenvolvimento melhora o desempenho do colaborador na sua função, mostrando que os mesmos possuem a consciência da importância do T\&D para o desenvolvimento da organização.

Segundo Czinkota (2001), a satisfação do cliente passa por quatro dimensões: confiabilidade, rapidez de resposta, garantia e empatia. A dimensão da confiabilidade trata da certeza que o cliente tem de que o produto oferecido pela empresa manterá os seus níveis de qualidade. Além disso, confiabilidade é a garantia que os funcionários mostrarão interesse em resolver algum problema que possa surgir com algum produto ou serviço adquirido pelo cliente.

$\mathrm{Na}$ Figura 5 pode ser visualizada a percepção dos colaboradores no que tange a contribuição dos treinamentos para o desempenho de função, bem como a melhoria na qualidade dos serviços prestados pela empresa. 
Figura 4: Contribuição da realização de treinamentos para o desempenho da função e melhoria na qualidade dos serviços prestados pela empresa.

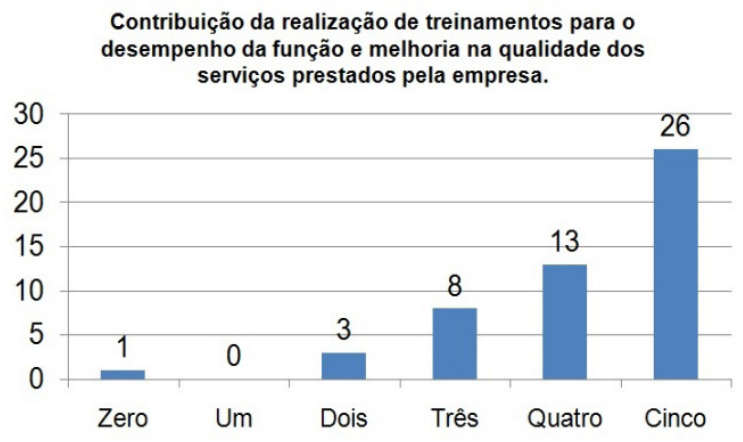

Conforme a Figura 5 é possível destacar que 26 colaboradores atribuíram pontuação máxima, 5, considerando excelente a contribuição da realização de treinamentos para desempenho da função e melhoria na qualidade dos serviços prestados pela empresa. Destaca-se ainda que apenas 3 colaboradores atribuíram 2 como sendo a nota mínima.

Já a visão por parte dos gestores pode ser conferida na Figura 6.

Figura 5: Visão dos gestores sobre a contribuição da realização de treinamentos para o desempenho da função e melhoria na qualidade dos serviços prestados pela empresa

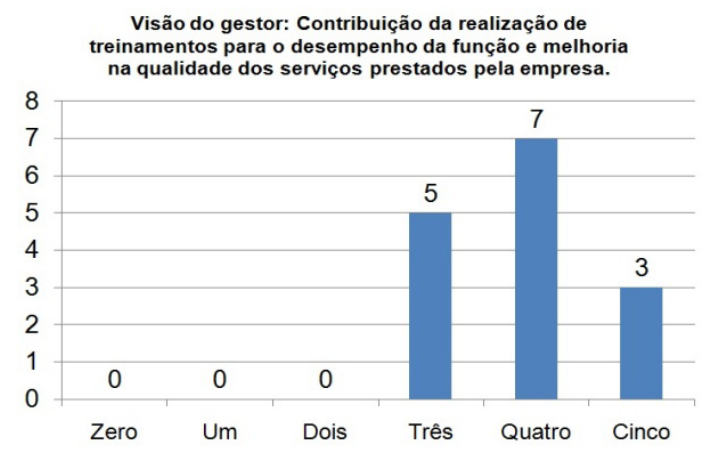

De acordo com os gestores (Figura 6), a contribuição dos treinamentos para o desempenho da função por parte do colaborador e a melhoria na qualidade dos serviços prestados pela empresa é considerada alta, recebendo pontuação de quatro pontos pela maioria deles. Os colaboradores e gestores concordam que os T\&D são muito importantes para a melhora na qualidade dos serviços prestados, mostrando que ambos estão cientes da sua importância para o crescimento da organização.

Apesar das diferenças constatadas em relação à realidade de cada setor, na opinião dos colaboradores e gestores é possível perceber que ambos atribuem uma pontuação alta para a importância e contribuição dos T\&D e que isso melhora do trabalho e desempenhado por eles e consequentemente influencia no crescimento da organização.

Após realizado o levantamento de dados e análise dos mesmos, tais como atividades e dificuldades de cada cargo, em seu respectivo setor, foram identificados todos os treinamentos solicitados, tanto pelo colaborador quanto pelo gestor. Para tornar visual, foi elaborada uma matriz de treinamento e desenvolvimento, que indica o setor, o cargo e treinamento a ser aplicado, conforme pode ser visualizado na Figura 7 que representa um recorte da matriz 
realizada a partir dos dados. Sendo que, em sua matriz geral são 14 setores com seus respectivos cargos e, 66 treinamentos diferentes sugeridos pelos colaboradores e gestores para atender a necessidade dos respectivos setores e cargos.

Figura 7: Matriz de Levantamento de Necessidades de T\&D

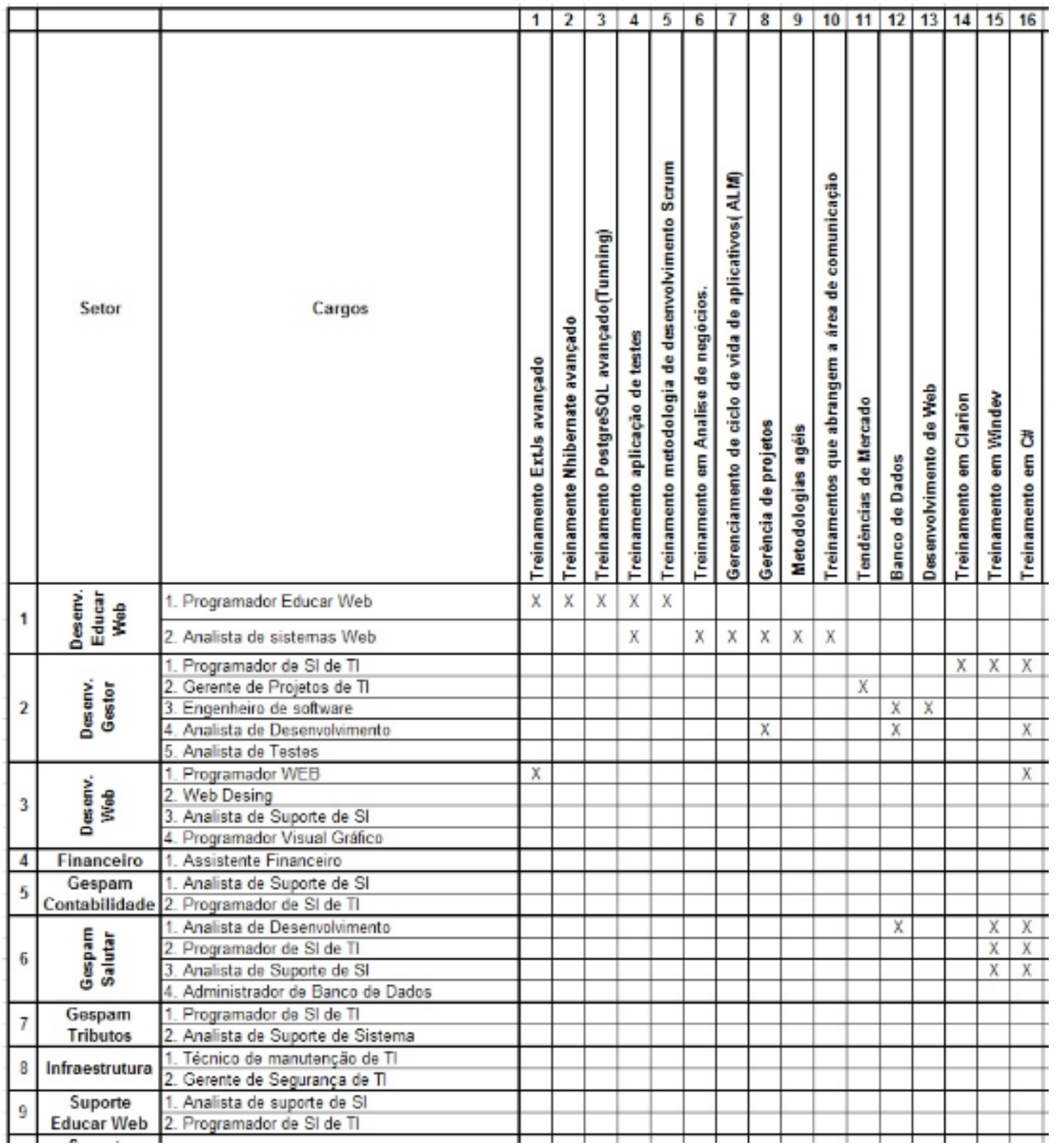

Considerando os treinamentos constantes na matriz, foi montada um quadro, onde mostra de forma prática a periodicidade de realização de cada um, periodicidade essa sugerida pelos colaboradores e gestores. Ele está apresentado na Figura 8, onde os setores, cargos e, os respectivos treinamentos são representados por números a partir da matriz original facilitando a apresentação da periodicidade. 
Figura 8: Periodicidade de realização dos treinamentos

\begin{tabular}{|c|c|c|c|c|c|c|c|c|c|c|c|c|c|c|}
\hline & Desenvol & vimento $E$ & ducar Web & & & & Financeiro & & & & & dministrativ & & \\
\hline Mensal & \begin{tabular}{|l|} 
Bimestral \\
\end{tabular} & Trimestral & Semestral & Anual & Mensal & \begin{tabular}{|l|} 
Bimestral \\
\end{tabular} & Trimestral & \begin{tabular}{|l|} 
Semestral \\
\end{tabular} & Anual & Mensal & Bimestral & Trimestral & Semestral & Anual \\
\hline & & & 1.1 .1 & & & & & \begin{tabular}{|l|}
4.1 .36 \\
\end{tabular} & & & & & \begin{tabular}{|l|}
11.1 .26 \\
\end{tabular} & \\
\hline & & & 1.1 .2 & & & & & 4.1 .37 & & & & & 11.1 .35 & \\
\hline & & & 1.1 .3 & & & Gesp: & am Contabil & lidade & & & & & 11.1 .59 & \\
\hline & & & 1.1 .4 & & & & & \begin{tabular}{|l|}
5.1 .38 \\
\end{tabular} & & & & & 11.1 .60 & \\
\hline & & & 1.1 .5 & & & & & 5.2 .39 & & & & & 11.1 .61 & \\
\hline & & & 1.2 .4 & & & & & & 5.2 .40 & & & & 11.2 .35 & \\
\hline & & & & 1.2 .6 & & & & & 5.2 .41 & & & Comercial & & \\
\hline & & & & 1.2 .7 & & & spam Salut & & & & & \begin{tabular}{|l|}
12.1 .8 \\
\end{tabular} & & \\
\hline & & & & 1.2 .8 & & & & 6.1 .12 & & & & & 12.1 .57 & \\
\hline & & & & 1.2 .9 & & & & 6.1 .15 & & & & & \begin{tabular}{|l|}
12.1 .62 \\
\end{tabular} & \\
\hline & & & & 1.2 .10 & & & & 6.1 .16 & & & & ontabilidad & & \\
\hline & & & 1.2 .54 & & & & & 6.1 .18 & & & & & & 13.1 .26 \\
\hline & & & & & & & & 6.1 .43 & & & & & & 13.1 .63 \\
\hline & Desenv & olvimento & Gestor & & & & & 6.2 .15 & & & & & & 13.1 .64 \\
\hline & & & & 2.1 .14 & & & & 6.2 .16 & & & Depar & rtamento $\mathrm{P}_{\mathrm{f}}$ & essoal & \\
\hline & & & & 2.1 .15 & & & & 6.2 .26 & & & & & \begin{tabular}{|l|}
14.1 .65 \\
\end{tabular} & \\
\hline & & & & 2.1 .16 & & & & 6.2 .35 & & & & & 14.2 .66 & \\
\hline & & & 2.2 .11 & & & 6.3 .15 & & & & & & & 14.3 .66 & \\
\hline & & & 2.3 .12 & & & & & 6.3 .16 & & & & & & \\
\hline & & & 2.3 .13 & & & & & 6.3 .18 & & & & & & \\
\hline & & & 2.3 .17 & & \begin{tabular}{|l|l|}
6.3 .26 \\
\end{tabular} & & & & & & & & & \\
\hline & & & & 2.3 .42 & & & & & 6.4 .26 & & & & & \\
\hline & & & & 2.4 .8 & & & spam Tribu & & & & & & & \\
\hline & & & & 2.4 .12 & & & & \begin{tabular}{|l|}
7.1 .52 \\
\end{tabular} & & & & & & \\
\hline & & & & 2.4 .16 & 7.2 .44 & & & & & & & & & \\
\hline & & & & 2.4 .18 & & & fraestrutur & & & & & & & \\
\hline & & & 2.5 .19 & & & & & & 8.1 .45 & & & & & \\
\hline & Deser & volvimen & to Web & & & & & & 8.1 .46 & & & & & \\
\hline & & & & 3.1 .1 & & & & & 8.2 .47 & & & & & \\
\hline & & & & 3.1 .16 & & Supo & rte Educar & Web & & & & & & \\
\hline & & & & 3.1 .18 & & & & 9.1 .35 & & & & & & \\
\hline & & & & 3.1 .20 & & & & 9.1 .48 & & & & & & \\
\hline & & & & 3.1 .22 & & & & 9.1 .49 & & & & & & \\
\hline & & & 3.1 .23 & & & & & 9.1 .50 & & & & & & \\
\hline & & & 3.1 .24 & & & & & 9.1 .51 & & & & & & \\
\hline 3.1 .25 & & & & & & & & 9.2 .21 & & & & & & \\
\hline & & & 3.1 .26 & & & & & & 9.2 .35 & & & & & \\
\hline & & & 3.2 .18 & & & & & 9.2 .52 & & & & & & \\
\hline & & & 3.2 .27 & & & & porte Gest & & & & & & & \\
\hline & & & 3.2 .28 & & & & & 10.1 .53 & & & & & & \\
\hline & & & 3.2 .29 & & & & & 10.1 .54 & & & & & & \\
\hline & & & 3.2 .30 & & & & & 10.1 .55 & & & & & & \\
\hline & & & 3.2 .31 & & & & & 10.1 .56 & & & & & & \\
\hline & & & 3.2 .32 & & & & & 10.1 .57 & & & & & & \\
\hline & & & 3.2 .33 & & & & & 10.1 .58 & & & & & & \\
\hline & & & 3.2 .34 & & & & & & & & & & & \\
\hline & & & & 33,35 & & & & & & & & & & \\
\hline
\end{tabular}

A periodicidade da realização dos T\&D é muito importante à medida que o colaborador sabe das suas necessidades e desta maneira pode expor quando a realização dos treinamentos se faz necessária. Nada melhor do que o colaborador que vive o dia a dia em contato direto com o cliente para saber quais informações precisa para conseguir ajudá-lo da melhor forma. É papel do setor de RH acompanhar estas demandas e disponibilizar aos colaboradores as ferramentas que se fazem importantes para o desenvolvimento do trabalho de cada em busca da excelência no atendimento.

Para que os resultados obtidos após a realização de cada treinamento pudessem ser avaliados, foi elaborada uma ferramenta de avaliação, com o objetivo de disponibilizar à gestão da empresa uma forma de mensurar a satisfação dos colaboradores em relação ao aproveitamento dos conhecimentos adquiridos para melhor o desempenho na função que exerce atualmente em seu cargo, no setor do qual faz parte. Apresenta-se de modo resumido a ferramenta criada pelos autores (Tabela 1). 
Tabela 1: Ferramenta de Avaliação dos Treinamentos

\begin{tabular}{|c|c|c|}
\hline $\mathbf{N}^{\mathbf{o}}$ & Questão & Alternativas \\
\hline 1. & Já conhecia o assunto abordado? & $\begin{array}{l}\text { ( ) sim, todos. } \\
\text { ( ) somente alguns. }\end{array}$ \\
\hline 2. & O treinamento realizado: & $\begin{array}{l}\text { ( ) não me proporcionou conheci- } \\
\text { mentos além dos já possuídos. } \\
\text { ( ) proporcionou-me novos con- } \\
\text { hecimentos sobre o assunto. }\end{array}$ \\
\hline 3. & $\begin{array}{l}\text { Durante o treinamento, tive oportunidade de reformular concei- } \\
\text { tos a respeito do assunto? }\end{array}$ & $\begin{array}{l}\text { ( ) sim. } \\
\text { ( ) não. }\end{array}$ \\
\hline 4. & No meu entender: & $\begin{array}{l}\text { ( ) muito pouco do que se falou } \\
\text { tem aplicação prática na minha } \\
\text { vida profissional. } \\
\text { ( ) grande parte do que se falou } \\
\text { tem aplicação prática na minha } \\
\text { vida profissional. }\end{array}$ \\
\hline 5. & $\begin{array}{l}\text { O treinamento realizado levou-me a uma reflexão sobre a con- } \\
\text { veniência de introduzir modificações: }\end{array}$ & $\begin{array}{l}\text { ( ) no meu comportamento. } \\
\text { ( ) nos processos de trabalho que } \\
\text { venho adotando. } \\
\text { ( ) nos planos que estabeleci. }\end{array}$ \\
\hline 6. & O treinamento: & $\begin{array}{l}\text { ( ) trouxe-me orientação se- } \\
\text { gura para a aplicação de novas } \\
\text { técnicas (processos) nas minhas } \\
\text { atividades. } \\
\text { ( ) trouxe-me a certeza de que es- } \\
\text { tou utilizando as técnicas (proces- } \\
\text { sos) mais adequados nas minhas } \\
\text { atividades profissionais. }\end{array}$ \\
\hline 7. & O treinamento ofereceu aos participantes: & $\begin{array}{l}\text { ( ) pouquíssimas } \\
\text { ( ) poucas } \\
\text { ( ) algumas } \\
\text { ( ) inúmeras oportunidades de } \\
\text { trocarem experiências e conheci- } \\
\text { mentos entre si. }\end{array}$ \\
\hline 8. & $\begin{array}{l}\text { Considero, de um modo geral, que os métodos e técnicas usa- } \\
\text { dos no treinamento foram: }\end{array}$ & $\begin{array}{l}\text { ( ) pouco adequados } \\
\text { ( ) adequados }\end{array}$ \\
\hline 9. & $\begin{array}{l}\mathrm{No}(\mathrm{s}) \text { próximo }(\mathrm{s}) \text { treinamento }(\mathrm{s}) \text { poderiam ser abordados o(s) } \\
\text { seguinte }(\mathrm{s}) \text { assunto }(\mathrm{s}) \text { : }\end{array}$ & \\
\hline 10. & Sugestões para os próximos cursos/treinamentos. & \\
\hline
\end{tabular}




\section{Considerações Finais}

A busca por excelência é algo que permeia as organizações e estar sempre atento às necessidades dos clientes é um ponto fundamental para o crescimento e permanência no mercado. Esta realidade está mais presente no ramo de $\mathrm{Tl}$ do que muitos imaginam, por se tratar de um setor onde as atualizações são constantes, as mudanças acontecem repetidamente, trazendo às organizações a necessidade de treinamento e desenvolvimento periódicos.

OT\&Dé uma ferramenta muito utilizada na busca por qualificação profissional em detrimento de qualidade nos serviços prestados. Para o gestor estar ciente de que seus colaboradores estão aptos a atender as necessidades dos clientes com a atenção e conhecimentos exigidos pelo mercado, esta ferramenta é fundamental. Para que a fidelização dos clientes aconteça, os colaboradores precisam ter confiança nas informações transmitidas pela organização contratada, o serviço prestado deve ser preciso e confiável acima de tudo.

Neste contexto, este estudo possibilitou a identificação dos treinamentos necessários para serem aplicados em uma empresa de TI, situada na cidade de Três de Maio - RS, bem como a elaboração de uma matriz de T\&D para a melhor visualização dos treinamentos a serem realizados em cada setor e cargo da empresa.

Através das análises realizadas, pode-se observar que a percepção dos colaboradores em relação as necessidade de T\&D é positiva, o interesse por parte dos mesmos para a realização destes também se mostra elevada, pois apesar de a empresa não oferecer treinamentos com certa periodicidade, alguns colaboradores buscam por conta própria às atualizações que acreditam ser importantes para o desenvolvimento da sua função.

Quanto aos gestores de cada setor, esses acreditam na contribuição dos T\&D para a melhora no desempenho de seus colaboradores. Todavia, não estão totalmente a par das necessidades que cada cargo possui, por isso, percebe-se que a necessidade de T\&D dos colaboradores é muito maior do que o seu gestor imagina.

Com o intuito de igualar as percepções sobre os T\&D este estudo resultou em uma matriz de T\&D, que ficará de posse da empresa na qual estão citados os treinamentos solicitados pelos gestores e colaboradores da organização, bem como a periodicidade que os mesmos gostariam que estes fossem realizados. Além disso, foi formulada uma ferramenta de avaliação dos treinamentos realizados que deverá ser respondida pelos colaboradores após a realização de cada T\&D, no qual a organização poderá acompanhar os benefícios que os T\&D irão trazer para a organização. Por fim, sugere-se que a matriz de T\&D seja atualizada periodicamente, a fim de que os treinamentos realizados acompanhem as necessidades que venham a surgir com o decorrer do tempo.

\section{Referências Bibliográficas}

ARAUJO, Luis César G. de. Gestão de Pessoas. - São Paulo: Atlas, 2006.

BERGAMINI, Cecília Whitaker. Avaliação de desempenho humano na empresa. 3. ed. São Paulo: Atlas, 1987.

BOOG, Gustavo G. Manual de Treinamento e Desenvolvimento ABTD: São Paulo MARKON Books, 1994.

BOOG, Gustavo G. Manual do treinamento e desenvolvimento ABTD. 3. ed. São Paulo: Pearson Markron Books, 2001. ISBN: 85-346-1302-8.

CHIAVENATO, Idalberto. Planejamento, recrutamento e seleção de pessoal: como agrupar talentos à empresa.7 Ed. Barueri, São Paulo: Manoele, 2009. ISBN: 978-85-204-2806-1. 
CZINKOTA, Michael R. Marketing: as melhores práticas. Porto Alegre, RS: Bookmann, 2001. ISBN: 85-7307779-4.

DUTRA, Joel Souza. Gestão de Pessoas: Modelo, Processos, Tendências e Perspectivas. São Paulo: Atlas, 2002.

DUTRA, Joel Souza. Administração de carreira: uma proposta para repensar a gestão de pessoas. São Paulo:Atlas, 1996.

GIL, Antonio Carlos. Gestão de Pessoas: Enfoque nos Papéis Profissionais. São Paulo: Atlas, 2001. ISBN 85-224-2952-9.

GÜLLICH, Roque Ismael da Costa; LOVATO, Adalberto. EVANGELISTA Mário dos Santos. Metodologia da Pesquisa:normas para apresentação de trabalhos: redação, formatação e editoração. Três de Maio: Ed. SETREM, 2007. ISBN: 85-99020-01-3.

LEME, Rogério. Avaliação de desempenho com foco em competência: a base para remuneração por competências. Rogério Leme - Rio de Janeiro: Qualitymark; 2006. 136p.:Anexo Inclui bibliografia ISBN 978-85-7303-769-2.

LOVATO, Adalberto. Metodologia da Pesquisa. Três de Maio: Ed. SETREM, 2013. ISBN: 978-85-99020-05-0.

MARRAS, Jean Pierre. Gestão estratégica de pessoas: conceitos e tendências. São Paulo: Saraiva, 2010.

MARRAS, Jean Pierre. Administração de recursos humanos: do operacional ao estratégico. $13^{a}$ ed. São Paulo: Saraiva, 2009. ISBN: 85-7413-026-5.

MARRAS, Jean Pierre. Administração de recursos humanos. 3. ed. São Paulo: Futura, 2000.

MILKOVICH, George T.; BOUDREAU, John W. Administração de Recursos Humanos. (Tradução: Reynaldo C. Marcondes) São Paulo: Atlas, 2000.

ROBBINS, P. S.; JUDGE, T. A.; SOBRAL, F. Comportamento Organizacional: Teoria e Prática no contexto Brasileiro. 14 ed.. São Paulo: Pearson Prentice Hall, 2011.

TACHIZAWA, Takeshy; FERREIRA, Vitor Cláudio Paradela; FORTUNA, Antônio Alfredo Mello. Gestão com Pessoas: uma abordagem aplicada às estratégias de negócios. São Paulo: FGV, 2001, cap. 9, 2 Edição.

XAVIER, Ricardo. Gestão de Pessoas na prática: desafios e as soluções. São Paulo: Editora Gente, 2006. 